\title{
Mortality rates of patients with COVID-19 in the intensive care unit: a systematic review of the emerging literature
}

\author{
Pipetius Quah" ${ }^{1 *}$, Andrew $\mathrm{Li}^{1}$ and Jason Phua ${ }^{1,2}$
}

The understanding of outcomes in the intensive care unit (ICU) for the coronavirus disease 2019 (COVID-19) remains poor. Studies have reported close to $100 \%$ mortality amongst patients requiring mechanical ventilation [1], and this together with the hypothesis that COVID19 may not cause classic acute respiratory distress syndrome (ARDS) has led to concerns regarding the use of mechanical ventilation $[2,3]$. We thus aimed to review the outcomes of ICU patients with COVID-19 from the existing literature.

We searched PubMed for studies published between Dec 1, 2019, and May 8, 2020, with at least ten ICU patients with COVID-19 and reported ICU mortality data. We excluded studies that had duplicate patients from other reports, did not provide data on ICU survival, enrolled only decedents, and excluded patients who were still hospitalised (Fig. 1 and Electronic Supplementary Material).

Several lessons can be surmised from Table 1, which outlines the 15 included studies conducted largely in countries worst hit by the pandemic. First, $56.1 \%$ of patients were still in the ICU at the time of study publication, and attempts to calculate mortality based on a sample of only deceased or discharged patients risk painting a skewed picture of reality [4].
Second, with the prior limitation in mind, the overall ICU mortality rate was $25.7 \%$. In China, with $14.1 \%$ of patients still in the ICU, the mortality rate was $37.7 \%$. These figures are not higher than the mortality rates of 35 to $45 \%$ seen in ARDS. Third, $29 \%$ of the ICU patients who died in the Chinese studies did not receive mechanical ventilation, and where systems experienced a surge of critically ill patients, up to $53.2 \%$ of patients who required ICU care were unable to receive it because of resource constraints [5]. In New York, 262 deaths occurred in hospital wards and outside the ICU, compared to 291 deaths in the ICU [4]. We hypothesise that rationing of ventilators and ICU beds in overwhelmed health systems may have resulted in attempts at postponing intubation, with a significant minority of patients received high-flow nasal cannula (13.7\%) and noninvasive ventilation (11.3\%) based on available data, despite uncertainty surrounding their roles.

We conclude that while there is a need for further studies which capture patients' final dispositions, the current preliminary data does not suggest unusually high ICU mortality rates for COVID-19. The poor outcomes seen in various studies may be related to rationing of resources in overwhelmed ICUs.

\footnotetext{
* Correspondence: pipetius_quah@nuhs.edu.sg

'Division of Respiratory and Critical Care Medicine, Department of Medicine, National University Hospital, National University Health System, Singapore, Singapore

Full list of author information is available at the end of the article
} 


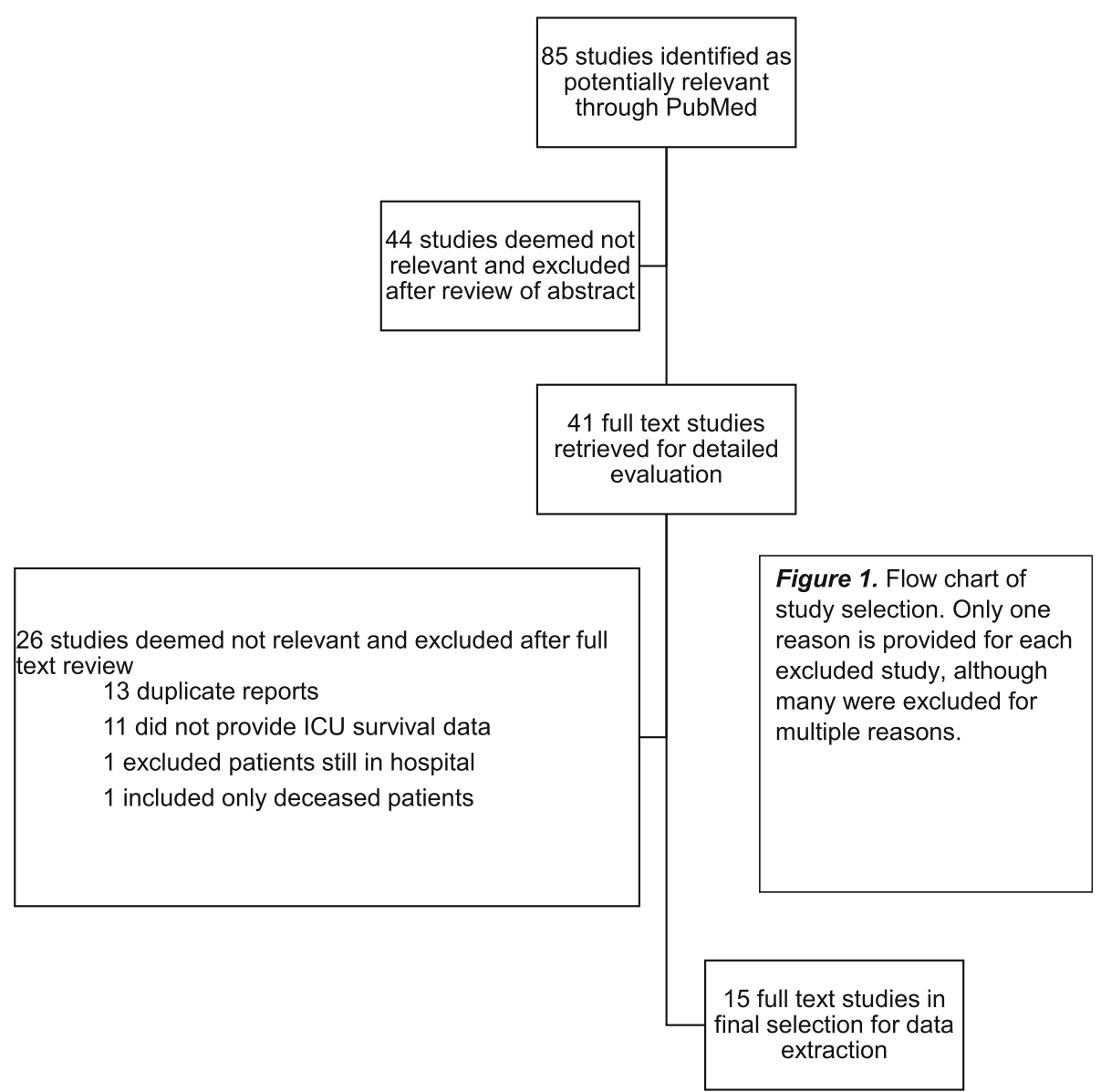

Fig. 1 Flow chart of the study selection. Only one reason is provided for each excluded study, although many were excluded for multiple reasons 


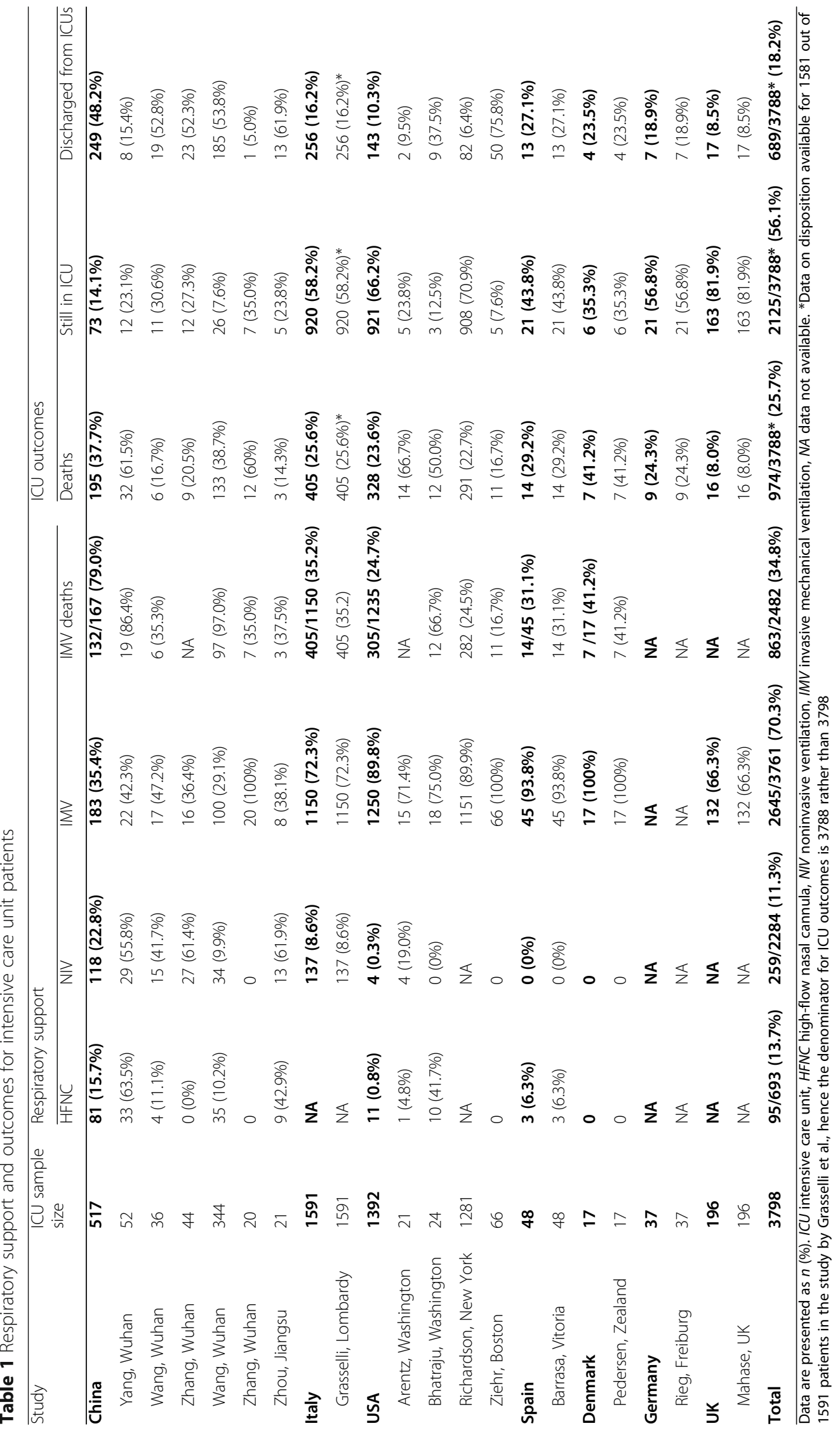




\section{Supplementary information}

Supplementary information accompanies this paper at https://doi.org/10. 1186/s13054-020-03006-1.

Additional file 1. Electronic Supplementary Material.

\section{Acknowledgements}

Not applicable.

\section{Authors' contributions}

All authors did the literature search. PQ and AL reviewed the articles and drafted the manuscript, which JP edited and supervised. All authors subsequently revised the manuscript. The author(s) read and approved the final manuscript.

\section{Funding}

This review was not funded by any organisation.

\section{Availability of data and materials}

The datasets generated during and/or analysed during the current study are available in the PubMed repository. The full list of included studies is available in the Electronic Supplementary Data (Appendix).

\section{Ethics approval and consent to participate}

No ethics approval and no patient consent were required for this study.

\section{Consent for publication}

Not applicable.

\section{Competing interests}

All authors declare no competing interests.

\section{Author details}

'Division of Respiratory and Critical Care Medicine, Department of Medicine, National University Hospital, National University Health System, Singapore, Singapore. ${ }^{2}$ Fast and Chronic Programmes, Alexandra Hospital, National University Health System, Singapore, Singapore.

Received: 12 May 2020 Accepted: 19 May 2020

Published online: 04 June 2020

\section{References}

1. Wang Y, Lu X, Chen H, Chen T, Su N, Huang F, Zhou J, Zhang B, Li Y, Yan F, Wang J. Clinical course and outcomes of 344 intensive care patients with COVID-19. Am J Respir Crit Care Med. 2020. https://doi.org/10.1164/rccm. 202003-0736LE.

2. Gattinoni L, Chiumello D, Caironi P, Busana M, Romitti F, Brazzi L, Camporota L. COVID-19 pneumonia: different respiratory treatments for different phenotypes? Intensive Care Med. 2020. https://doi.org/10.1007/ s00134-020-06033-2.

3. Li X, Ma X. Acute respiratory failure in COVID-19: is it "typical" ARDS? Crit Care. 2020;24(1):198. https://doi.org/10.1186/s13054-020-02911-9.

4. Richardson S, Hirsch JS, Narasimhan M, Crawford JM, McGinn T, Davidson KW, the Northwell C-RC, Barnaby DP, Becker LB, Chelico JD, Cohen SL, Cookingham J, Coppa K, Diefenbach MA, Dominello AJ, Duer-Hefele J, Falzon L, Gitlin J, Hajizadeh N, Harvin TG, Hirschwerk DA, Kim EJ, Kozel ZM, Marrast LM, Mogavero JN, Osorio GA, Qiu M, Zanos TP. Presenting characteristics, comorbidities, and outcomes among 5700 patients hospitalized with COVID-19 in the New York City area. JAMA. 2020. https:// doi.org/10.1001/jama.2020.6775.

5. Du RH, Liu LM, Yin W, Wang W, Guan LL, Yuan ML, Li YL, Hu Y, Li XY, Sun B, Peng P, Shi HZ. Hospitalization and critical care of 109 decedents with COVID-19 pneumonia in Wuhan, China. Ann Am Thorac Soc. 2020. https:// doi.org/10.1513/AnnalsATS.202003-2250C.

\section{Publisher's Note}

Springer Nature remains neutral with regard to jurisdictional claims in published maps and institutional affiliations. 